basis, but also to visualise the problem of radium therapy in cancer in all its complexity and yet not be baffled by it.

For some years it has been recognised that rodent ulcer is a disease very amenable to this form of therapy, and this is confirmed in the data before us. Of later years, the value of radium in cancer of the cervix uteri has been maintained, and there is a considerable mass of evidence in this report which substantiates the claim. In cancer of the breast, the data show an increasing use of radium combined with surgical operation, but the full value of this combination depends largely upon the nature of the surgical operation and the extent to which it is possible to insert the radium at places of likely extension of the disease. We gather from the report that the results obtained by the use of radium in malignant disease of the mouth, jaw, or throat, continue in most cases to be disappointing. This appears to be chiefly due to local anatomical and surgical difficulties rather than to any specific resistance of the tumours themselves.

Non-malignant conditions have also been investigated. It is satisfactory to find in the reports from three independent centres, a practical uni- formity in the dose of radium employed in the treatment of uterine fibromata and of menorrhagia, and an equal measure of success in the results.

Recognising that progress in therapy is largely dependent upon collateral researches, the Medical Research Council, through its Radiology Committee, has, from the inception of this scheme, supported such researches which have so far been of physical or biological character. Sir Ernest Rutherford reports upon the disintegration of the elements by means of alpha rays.

Researches of a biological character are separately detailed as having been carried out by Mr. Timbrell Fisher in osteo-arthritis, by Dr. J. C. Mottram on changes in the intestinal tract resulting from radiation, and by Prof. S. Russ upon the determination of lethal doses of radiation for animal tumours.

The publication as a whole is worth serious study, for it is a finger-post along the road of treatment in malignant disease. While there are no extravagant claims made for it, it cannot be doubted that radium is a valuable instrument in the treatment of cancer and other diseases, and we look with confidence to the results which these investigations may provide in the near future.

\title{
Chemistry in India
}

T'HE success which has attended the inauguration of the Indian Science Congress, and the great increase in the amount of new work in chemistry which has occurred in the Indian Empire during the past ten years, has led to the establishment of an Indian Chemical Society, under the presidency of Sir P. C. Rây, with offices at 92 Upper Circular Road, Calcutta; the first number of the Quarterly Journal of the Society has now appeared.

Hitherto, chemical papers emanating from India have been published either in the Journals of the Chemical Societies of London or America, or in one or other of the larger continental publications. The disadvantages attaching to this procedure became more and more obvious as the volume of new work increased, because the older Journals are becoming over-burdened, and the need for economy of space necessitated frequent correspondence between authors and editors, entailing grave loss of time in the cases of countries so far distant as India.

Apart, therefore, from the pleasure with which all British chemists will welcome this national effort on the part of India, there will be general agreement among them that the scheme of decentralisation of publications within the British Empire which it implies is the only one which can lead to the rapid and adequate publication of new knowledge and tend ultimately to the real advancement of chemistry. Optimists may dream of the time when there will be one Chemical Society and one Chemical Journal for all the English-speaking races, but until the transportation of matter can be accomplished with a velocity approaching that of light, distance must always act as an obstacle to any such plan, however desirable it may be.

The new Journal is a welcome illustration of the development which has taken place in Indian chemistry during recent years. There are thirteen papers, and only one of these is published under English names. The remaining papers are published by Indians and come from all parts of the Indian Empire. Four of them emanate from the College of Science, Calcutta, and this is as it should be, because, for many years past, this Institution has been the backbone of chemical research in India. The other communications come from Allahabad, Baroda, Dacca, Cuttack, Benares, and Madras, and constitute a series of which the organising committee and editor have every reason to be proud.

The Journal is well printed, and doubtless the structural formulæ, which seem, at times, to have given the printer some trouble, will improve with experience. Older chemists with impaired eyesight will probably quarrel with the colour of the cover the printing on which is most difficult to read, but these are minor points and do not detract from the value of what is essentially a most creditable and important production.

\section{The Ross Barrier.}

IN a paper to the Royal Geographical Society on January I9, Mr. C. S. Wright gave an account of the Ross Barrier and the mechanism of ice movement. There is now little doubt that the barrier is bounded by high land on all sides except the north, although the ranges between Edward Land and the Maud ranges have still to be discovered. The area of this ice sheet may be given as approximately I 50,000 square miles. Ample proof is forthcoming that the seaward edge of the barrier is afloat, although it is probably aground at the site of Amundsen's winter quarters east of the Bay of Whales. Observations have proved that the slope of the barrier is very slight and this must be interpreted as evidence that the barrier is afloat even quite close to its southern edge.

The barrier movement is compounded of the result due to the thrust of glaciers from the plateau on the west, south and east, and movement due to the flattening and outward extension of a thick mass of ice under its own weight. Mr. Wright gave evidence in support of the view that these two causes are roughly of equal importance. If no movement were

NO. 2883 , VOL. I I 5$]$ 
contributed by glacier thrust, certainly the general level character of the barrier surface would be maintained, provided that the barrier rests on a warm frictionless plane-the sea. If it rested on land, the bottom friction would be high, the temperature low, and the movement slight. On the other hand, the fact that there is little or no local thickening in the region of the outflow of land glaciers to the barrier must indicate an efficient water circulation beneath it. In that case, local thickening would involve local depression and increased local melting from below; thus the general surface level would be maintained. It is not possible to suppose that floating glacier tongues played no part in the formation of the barrier. Such tongues are common in the Antarctic and many of them extend far out to sea.

The barrier had probably a twofold origin. Numerous floating ice tongues from the large glaciers at the back of the Ross Sea were no doubt cemented together by sheets of sea-ice formed in situ in the areas between them. The latter process would entail the formation of sea-ice and precipitation of snow thereon at a rate exceeding that at which it melts below.

These conditions were certainly possible during the period of maximum glaciation, even if they do not now occur. Observations have shown that the rate of increase in thickness of sea-ice does not decrease largely as the thickness increases. This points to the fact that conduction of heat from below is not the sole cause of growth. At present there are sheltered positions in which sea-ice can form and maintain itself for more than one year. Mr. Wright, in discussing the mechanism of movement of ice, shows how uncertain and incomplete are our data for the rate of advance of the barrier, its snowfall and contributions to its mass from land glaciers.

\section{University and Educational Intelligence.}

ABERDEEN.-The University Court has resolved to institute a lectureship in clinical chemistry.

Dr. Alexander Bowman has been appointed lecturer on the scientific study of fisheries.

CAMBRIDGE.-The Statutory Commissioners have been approached by a number of members of the Senate on the question of the retiring age for professors, which was fixed in the recommendations of the Royal Commission at 65 years. The Commissioners favour the proposal that the Board of Electors to a professorship may, when a professor reaches the age of sixty-five, invite him to hold office up to an age not exceeding seventy, if it is believed that the interests of the University will best be served thereby. The Board of Electors is to be precluded from making any fresh election of a professor who is already more than 65 years of age, but if a candidate is elected who is over sixty, he may be elected to hold office up to the age of seventy.

Mr. W. B. R. King, Magdalene College, has been reappointed assistant to the Woodwardian professor of geology. On the nomination of the Department of Scientific and Industrial Research, Sir Joseph Broodbank is being appointed to the committee of management of the Low Temperature Station for Research in Biochemistry and Biophysics.

The Special Board for Mathematics has reported to the Senate, asking the University to take steps to enable the Tyson Medal to be struck in bronze, instead of in gold as at present, and to be accompanied by a prize in money.

The Board for Engineering Studies has recommended certain changes in the regulations for the
Mechanical Sciences Tripos, including the sub-division of certain of the advanced subjects necessary for a First Class. Thus electricity and magnetism is replaced by electric power and electric signalling, and theory of structures and strength of materials by theory of structures (civil) and theory of structures (mechanical). Mechanics of machines also figures for the first time as a separate subject. It is proposed also to establish jointly with the University of Birmingham a diploma in coal-mining engineering, for which the general course of engineering at Cambridge should count as part of the training, this course to be followed by four months' practical experience in a coal mine and a year's course in mining at the University of Birmingham.

EDINBURGH.-At the meeting of the University Court on Monday, January I9, the resignation of Sir Harold J. Stiles, Regius professor of clinical surgery in the University, to take effect on March 20 , was announced. The Principal expressed the great regret which was felt by the Court, the high appreciation of the eminent services which Sir Harold Stiles had rendered to the University, and the sense of the deep loss which would be sustained upon his retirement, not by the Court alone but by the University as a whole.

The Library of the Geology Department of the University has been indebted for a number of years to the late Sir Archibald Geikie for donations of valuable geological literature. The last consignment has recently been received from his daughters. This Library was gradually built up and strengthened by the Geikie brothers who in turn filled the chair of geology.

London.-A course of eight free public lectures on "The Chemistry of the Internal Secretions" will be given by Mr. E. C. Dodds, at the Middlesex Hospital Medical School, at 5 o'clock, on February 3, 5, 10, 12, I7, I9, 26, and March 3; one of four by Dr. J. Duncan Scott, on "The Medullary Centres," at the Physiology Department of St. Bartholomew's Hospital Medical College, 6 Giltspur Street, E.C., at 5 o'clock, on February II, I8, 25, and March 4; and one of four by Sir William I. de Courcy Wheeler, at St. Bartholomew's Hospital Medical College, at 5 o'clock, on February I6, I7, I8, and 19, on "Some Practical Considerations and Experiences in the Conservative Treatment of Fractures of the Pelvis and the Lower Extremity." Two courses of free public lectures at Birkbeck College are announced, namely, four, by Dr. G. G. Coulton, on " Medieval Education" (February 2, 9, I6, and 23), and three, by Prof. E. N. da C. Andrade, on " The Structure of the Atom" (February 5, I2, and I9). The lecture hour in each case will be 5.30 , and no tickets will be required.

St. Andrews.--The degree of Ph.D. has been conferred on Mr. G. R. Ross for a thesis entitled "The Serological and Immunological Characteristics of Tubercle Bacilli after Extraction with Fat Solvents."

Applications are invited for two lectureships at University College, Leicester, viz. in physics and in chemistry. The applications must reach the secretary of the college by February $\mathrm{I}_{3}$ at latest.

DR. WALTER MAKowĖR has been appointed professor of science at the Royal Military Academy, in succession to Prof. J. Young, retired, Dr. de Mouilpied, who was to have filled this post, resigned without taking up the appointment. Dr. Walter Makower, who was lately chief physicist to the Dunlop Rubber Company, was for many years lecturer in physics at the University of Manchester. 